\title{
Blind mole rat (Spalax leucodon) masseter muscle: structure, homology, diversification and nomenclature
}

\author{
A. Yoldas ${ }^{1}$, M. Demir ${ }^{1}$, R. Ilgun², M.O. Dayan ${ }^{3}$ \\ ${ }^{1}$ Department of Anatomy, Faculty of Medicine, Kahramanmaras University, Kahramanmaras, Turkey \\ ${ }^{2}$ Department of Anatomy, Faculty of Veterinary Medicine, Aksaray University, Aksaray, Turkey \\ ${ }^{3}$ Department of Anatomy, Faculty of Veterinary Medicine, Selcuk University, Konya, Turkey
}

[Received: 10 July 2018; Accepted: 23 September 2018]

\begin{abstract}
Background: It is well known that rodents are defined by a unique masticatory apparatus. The present study describes the design and structure of the masseter muscle of the blind mole rat (Spalax leucodon). The blind mole rat, which emerged 5.3-3.4 million years ago during the Late Pliocene period, is a subterranean, hypoxia-tolerant and cancer-resistant rodent. Yet, despite these impressive characteristics, no information exists on their masticatory musculature.

Materials and methods: Fifteen adult blind mole rats were used in this study. Dissections were performed to investigate the anatomical characteristics of the masseter muscle.

Results: The muscle was comprised of three different parts: the superficial masseter, the deep masseter and the zygomaticomandibularis muscle. The superficial masseter originated from the facial fossa at the ventral side of the infraorbital foramen. The deep masseter was separated into anterior and posterior parts. The anterior part of the zygomaticomandibularis muscle arose from the snout and passed through the infraorbital foramen to connect on the mandible.

Conclusions: The construction of the deep masseter and zygomaticomandibularis muscles were of the Myomorpha type. Further studies are needed to reveal features such as muscle biomechanics, muscle types. (Folia Morphol 2019; 78, 2: 419-424)
\end{abstract}

Key words: anatomy, masseter muscle, Spalax leucodon

\section{INTRODUCTION}

Spalax leucodon superspecies is a group of wild rodents belonging to the Spalacidae family. The general consensus is that they emerged 5.3-3.4 million years ago (Late Pliocene period) around Anatolia and spread to Anatolia, the Balkans, the Russian steppes, the Middle East and North Africa. Morphological investigations show that two species (Spalax leucodon and Spalax ehrenbergi) of blind mole rats are found in Turkey [18]. The Spalacidae, or spalacids, are a family of rodents in the large and complex superfamily Muroidea [24, 25].
Animals from the Spalax leucodon spend the vast majority of their life in their underground burrows and tunnel systems. Their eyes are atrophied and the orbits are covered with skin. They are different from other rodents, with their external ear pinnae and atrophied tails. The average weight of a mole rat is 100-570 g [9].

Spalax leucodon is an exceptional species that is able to survive in underground galleries at an oxygen level of $7 \%$, while possessing certain morphological, physiological and behavioural characteristics under 
routine underground conditions with high carbon dioxide levels. Therefore, they are used as an animal model in hypoxic studies [21, 31]. Moreover, the species can live up to 21 years, and, interestingly, spontaneous tumours have never been observed [10]. They also have different structures of haemoglobin [19], myoglobin [42], respiratory system [17] and myocardial performance [8].

It is well known that there is a significant relationship between lifestyle, feeding strategy and chewing muscles in mammalian species. Therefore, the morphology of the masticatory muscles differs from species to species. Rodents, the largest group of mammals, are unique due to their extraordinary masticatory apparatus. The masseter muscle comprises $60-80 \%$ of the total masticatory muscle mass in rodents $[5,33]$. The morphological properties of the masseter muscle can be changed by the type of masticatory activity of the rodents. The structure of the masseter muscle has also been an important criterion in the classification of rodents [2]. In terms of masticatory muscle anatomy, rodents can be divided into four classes: Protrogomorpha (primitive rodents), Sciuromorpha (squirrels), Myomorpha (rats and mice), and Hystricomorpha (porcupines and the South American caviomorph rodents) [23].

Kangaroos, wallabies, and rat-kangaroos (superfamily Macropodoidea) are Australian dominant mammalian herbivores. They vary markedly in dietary preferences, similar to the artiodactyl ungulates of other continents. Some species utilise many different foods, whereas others are much more specific in their choice of food items. Different foods require processing in different ways. Masticatory morphology represents a trade-off between what is required to effectively break down food and phylogenetic constraints. The correlation between feeding strategy and morphology in kangaroos has been investigated by several researchers, and the results have indicated differences in dental morphology and behaviour associated with the feeding types [35].

Rodents have a very large population and constitute more than half of the known mammalian species. The blind subterranean mole rat, Spalax leucodon superspecies, is a group of species of wild rodents. Many studies [1, 4, 6, 12, 14, 20, 35, 36, 39-41] have been conducted on the masseter muscles of rodents living in different ecological conditions. However, information about the masseter muscle of the Spalax genus is limited. This study aims to describe the macro-anatomic structure of the masseter muscle and investigate its relationship in S. leucodon and other rodents.

\section{MATERIALS AND METHODS}

Animals and experimental procedure

For this study, we collected 11 male and 4 female mole rats (Spalax leucodon) from the Aksaray Province of Turkey. All the animals were captured by villagers. Mole rats were taken to the Department of Anatomy, Faculty of Veterinary Medicine, Aksaray University, in well-ventilated cages (dimensions: $1 \times 0.7 \times 1 \mathrm{~m}$ ). All experimental procedures were approved by the Animal Experiments Local Ethics Committee of the Afyonkarahisar Kocatepe University (approval no. 06.01.2012/1242).

At room temperature $\left(20^{\circ} \mathrm{C}\right)$, the animals were anaesthetised with an intraperitoneal injection of a combination of $10 \mathrm{mg} / \mathrm{kg}$ xylazine (Rompun enj; Bayer Turk Chemistry Industry Ltd. Corp., Istanbul, Turkey) and $100 \mathrm{mg} / \mathrm{kg}$ ketamine $\mathrm{HCl}$ (Ketalar Eczacıbası; Istanbul, Turkey). Fifteen mole rats were killed by exsanguination of the left common carotid artery under anaesthesia. Animals were then fixed in formal saline (buffered $4 \%$ formaldehyde solution with $0.12 \mathrm{M} \mathrm{NaCl}$ ) and stored in $70 \%$ ethanol. Mole rats were dissected to further investigate and examine the anatomy of the masticatory muscles. For each masticatory muscle, the positions of its origin and insertion on the skull and the mandible were carefully inspected, as well as the direction of muscle fibres, in order to establish mycological maps. Finally, the findings were recorded and photographed using a Canon Eos $600 \mathrm{~d}$. After being photographed, maceration was performed to describe the cranial bones and the attachment of the masseter muscle, as in previous studies. The bone structures related to the masseter muscle were examined based on the work done by Ozkan [27].

\section{RESULTS}

The masseter muscle consisted of three main parts: superficial masseter, deep masseter and zygomaticomandibularis muscle.

\section{Superficial masseter}

It is the outermost layer of the masseter muscle with a water-drop shape. The superficial masseter was observed to cover two-thirds of the anterior deep masseter. However, the anteroventral portion of the superficial masseter was clearly distinguishable from the deep masseter muscle with the naked eye 
(Figs. 1-3). The aponeurosis of the origin of the superficial masseter formed a strong flattened tendinous (Figs. 2, 3). This aponeurosis originated from the oval shallow fossa and was located on the inferior portion of the zygomatic root, on the ventrolateral face of the maxilla. After its origin, the musculoaponeurotic fibres had an emphasised ventro-aboral obliquity, fanned out on the large part of the anterior deep masseter and the posteroventral portion of the posterior deep masseter, and continued with a massive muscular belly that could be seen on the angle and ventral edge of the angular process of the mandible. The muscle fascicles were extended to the back of the mandible and inserted between the posterolateral surface of the angle of the mandible and the border of the masseteric fossa. Most of the muscle fascicles on the dorsal edge of this muscle were also integrated into the aponeurosis of the deeper masseteric layer, making the separation of these two parts of the masseter difficult (Figs. 2, 3).

\section{Deep masseter}

The deep masseter was divided into an anterior and a posterior part. The anterior deep masseter originated from the zygomatic plate, which had a narrow pouch, and was horizontally located on the anteroventral face of the zygomatic process of the maxilla (Fig. 1). The point of origin of the anterior part of the deep masseter filled the pouch. After its origin, it passed horizontally, placed under the superficial masseter, and inserted on the masseteric ridge, placed rostral of the fossa mandible (Figs. 1-3).

The posterior deep masseter originated along the caudoventral edge of the zygomatic arch and ran ventral-caudal to insert into the shallow masseteric fossa, located on the lateral face of the mandible (Figs. 1-3).

\section{Zygomaticomandibularis muscle}

It was the innermost layer of the masseter muscle and consisted of two parts: pars anterior and pars posterior.

The pars anterior originated from the medial face of the temporal process of the zygomaticum bone. A part of the pars anterior, the infraorbital zygomaticomandibularis muscle also rose from the medial surface of the maxillary and the root of the zygomatic arch. Its muscle fibres extended through the infraorbital foramen, which was wide and ovoid, and combined with the main part of the pars anterior.

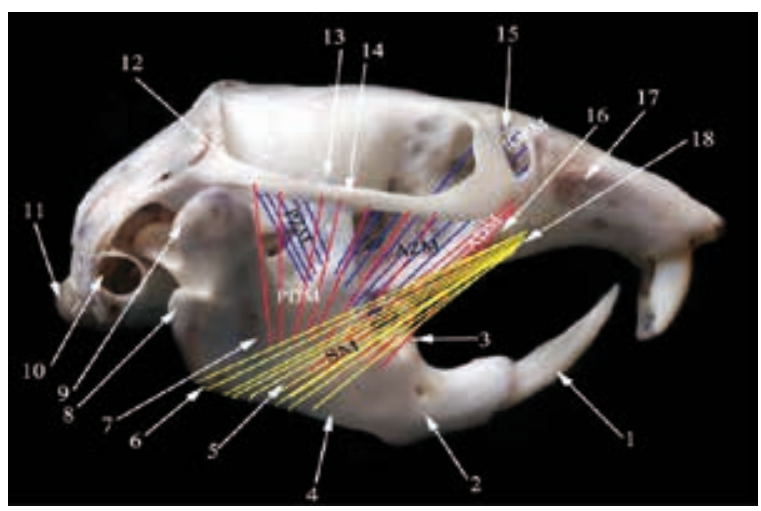

Figure 1. General view of skull and origins-insertions of the masseter muscle in $S$. leucodon (lateral view); 1 - incisor teeth; 2 mental foremen; 3 - molar teeth; 4 - mandibular body; 5 masseteric ridge; 6 - mandibular angle; 7 - masseteric fossa; 8 - angular process; 9 - condyloid process; 10 - external acoustic pore; 11 - occipital condyle; 12 - temporal process of the zygomatic arch; 13 - coronoid process; 14 - zygomatic arch; 15 - infraorbital foramen; 16 - the area of origin of the anterior deep masseter (the zygomatic plate); 17 - maxilla; 18 - the area of origin of the superficial masseter; SM (yellow lines) - the superficial masseter; PDM (red lines) — the posterior deep masseter; ADM (red lines) — the anterior deep masseter; PZM (purple lines) — the posterior zygomandibular masseter; AZM (purple lines) - the anterior zygomandibular masseter; IOZM (purple lines) — infraorbital part of zygomandibular masseter.

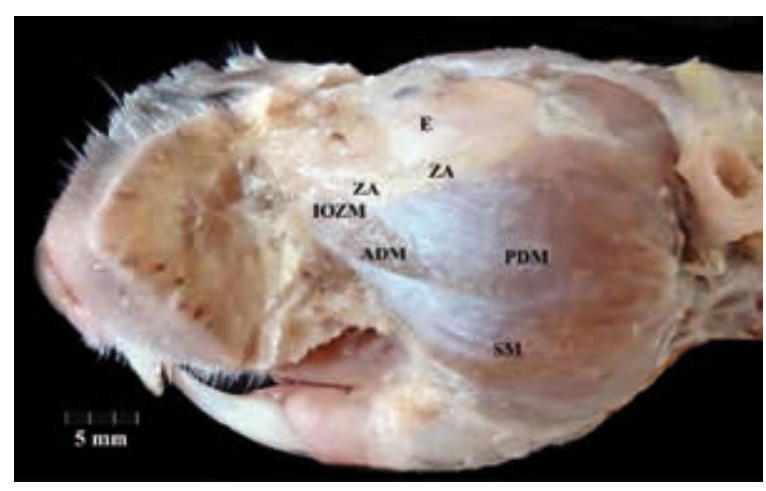

Figure 2. Lateral view of masseter muscles; ADM - anterior deep masseter; IOZM — infraorbital part of the zygomaticomandibularis; PDM - posterior deep masseter; SM — superficial masseter; E - atrophied eye; ZA — zygomatic arch.

Then, it ran caudoventrally and inserted onto the anterior root of the coronoid process (Figs. 1, 3, 4).

The pars posterior originated on the ventral and medial surface along the posterior half of the zygomatic arch. The fibres of the posterior were weaker than those of the anterior. The fibres of the pars posterior passed straight rostroventrally to insert on the fosse, which was located on lateral surface of the coronoid process (Figs. 1, 4). 


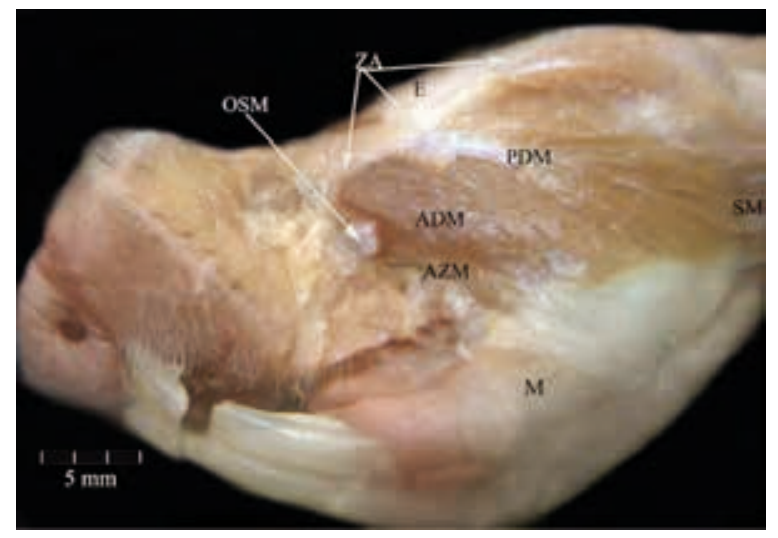

Figure 3. Lateral-ventral view of masseter muscles (the SM and the part of the PDM have been removed); SM - superficial masseter (removed); OSM — the origin of SM; ADM — anterior deep masseter; PDM - posterior deep masseter; AZM — anterior zygomaticomandibularis; ZA — zygomatic arch; E — atrophied eye; $\mathrm{M}$ - mandibular body.

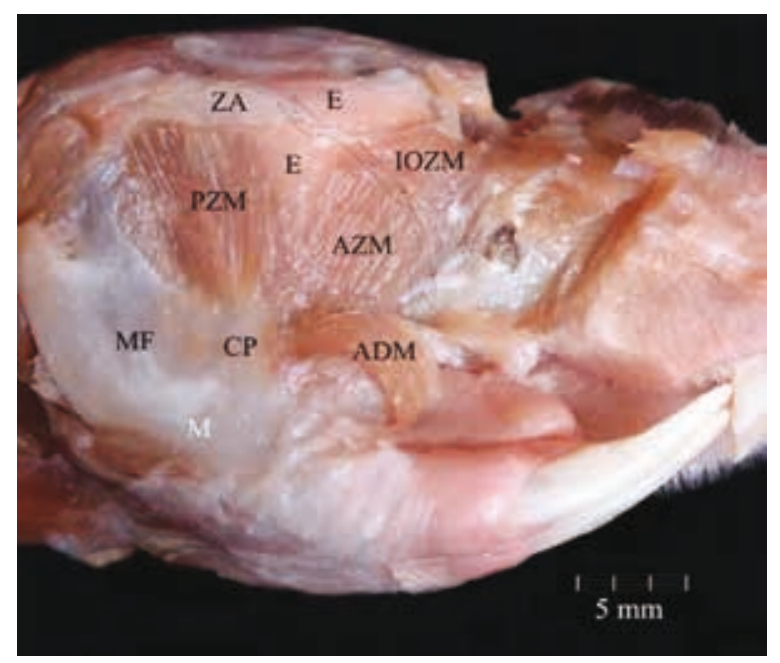

Figure 4. Left lateral view of masseter muscles (the SM, ADM, PDM, the superior of ZA and the process frontal of the zygomatic arch have been removed); ADM - anterior deep masseter (removed); AZM — anterior zygomaticomandibularis muscle; PZM — posterior zygomaticomandibularis muscle; IOZM inferior part zygomaticomandibularis muscle; ZA - zygomatic arch; $\mathrm{E}$ - atrophied eye; $\mathrm{M}$ - mandibular body; $\mathrm{CP}$ — coronoid process; MF — masseteric fossamasseter.

\section{DISCUSSION}

Since rodents are the biggest mammalian group, the classification of the masseter muscle of rodents is controversial. For many years, there have been arguments about the parts of the masseter muscle of mammals. Some researchers $[1,5,35,41]$ reported that the masseter muscle of rodents had three main parts: the superficial masseter, the deep masseter and the zygomaticomandibularis muscle. However, Hiiemae and Houston [14] reported that, in rodents, the masseter muscle was divided into two parts: the superficial masseter and the deep masseter. In our sample, the masseter muscle was observed with three main parts, as described in some rodents $[5-7,12]$.

It was reported that, in some rodents, the superficial masseter had two parts (superficial and lateral) $[12,19]$. On the other hand, Miller and Gidley [22] and Howell [16] expressed that these two muscles were the same. In our samples, the superficial masseter was a single part and originated from the maxillary bone via a flattened and strong tendon, as in Muroids, Geomyida $[15,28]$, rats $[14,36]$, Laotian rock rats [12] and Marsupialia [35].

Some researchers described the superficial masseter in squirrels as originating from the masseteric tubercle, which is under the infraorbital foramen [41]. However, in our case, the masseteric tubercle was absent and the ovoid fossa had developed instead. This finding is supported by some studies conducted on squirrels [32], guinea pigs [37] and rats [11].

The deep masseter, namely the lateral masseter in some rodents [39], consists of two separate parts in rodents $[5,41]$. This finding is consistent with our report. However, the deep masseter has been noted to be a single part in guinea pigs [5], squirrels [33] and mice [1].

Due to the anatomical variety of the zygomatic plate, the morphologic structure of the origin of the anterior deep masseter can be different in rodents. Thus, the structure of the zygomatic plate is critical for the classification of rodents. The anterior deep masseter originates from the zygomatic plate $[5,6]$. However, unlike some Sciuromorpha and Hystricomorpha, in our samples, the zygomatic plate was settled in the anteroventral face of the zygomatic process of the maxilla. It did not expand onto the rostrum, as in fossil rodents [34] and Aplodontia rufa, which is the only living protrogomorphous rodent [7].

In our samples, the posterior deep masseter originated from the part of the zygomatic arch that terminated on the mandible fossa, with the same pattern as in squirrels [5, 33, 41], rats [5] guinea pigs [26], Aplodontia rufa and Marmota monax [7].

Some researchers [11] did not make any comments about the presence of the zygomaticomandibularis muscle in rats. Whereas Hiiemae and Houston [14] could not distinguish the zygomaticomandibularis muscle, and thus regarded it as a part of the deep 
masseter, others $[3,4,29]$ ignored this muscle. This muscle was also termed the medial muscle of the masseter muscle by some researchers [12]. We saw that the zygomaticomandibularis muscle was the innermost layer of the masseter, and was divided into two parts (the pars anterior and pars posterior); this is the same as in squirrels, rats, guinea pigs [5], mice [1], Laotian rock rats [12], mountain beavers and Marmota monax [7].

In some living Myomorpha rodents, such as Spalax sp., Myospalax sp., and Oxycmterus sp., the zygomasseteric structure has been shown to be an intermediate type between the hystricomorphous and myomorphous types. The diameter of the infraorbital foramen is larger in Hystricomorpha than in Myomorpha [20]. Furthermore, Hystricomorpha and Myomorpha, unlike Sciuromorpha have the infraorbital portion of the pars anterior of the zygomaticomandibularis muscle, which passes through the infraorbital foramen $[5,33,41]$. This portion is enlarged and covers most of the lateral wall of the rostrum in Hystricomorpha. In our specimens, although this portion existed, it was not as wide as described in hystricomorphous [36].

In rats, squirrels, guinea pigs [5] and Laotian rock rats [12], the anterior part of the zygomaticomandibularis muscle is stronger than the posterior, as in the blind mole rat. Moreover, a large posterior part of the zygomaticomandibularis muscle is also found in carnivores, in which it may function to resist forces produced by struggling prey [30].

In some Hystricomorpha rodents, an extra section of the posterior part of the zygomaticomandibularis muscle has been distinguished and named the muscles masseter lateralis profundus [40], the posterior masseter $[7,13]$, the pars posterior or the deep division [38]. We did not find any evidence of this part, which was separated from the posterior part of the zygomaticomandibularis muscle

\section{CONCLUSIONS}

This study is a detailed description of the morphological features of the Spalax leucodon complex masseter muscle. The data were compared to those for other rodents and may contribute to enhancing our morphological knowledge regarding the masticatory musculature in mammals.

\section{REFERENCES}

1. Baverstock H, Jeffery NS, Cobb SN. The morphology of the mouse masticatory musculature. J Anat. 2013;
223(1): 46-60, doi: 10.1111/joa.12059, indexed in Pubmed: 23692055.

2. Brandt JK. BeitragezurnahernKenntniss der SaugethiereRusslands. Memoires de l'Acade' mielmpe' riale des. Sciences de St Petersbourg. 1855; 69: 1-375.

3. Bresin A, Bagge U, Kiliaridis S. Adaptation of normal and hypofunctional masseter muscle after bite-raising in growing rats. Eur J Oral Sci. 2000; 108(6): 493-503, doi: 10.1034/j.16000722.2000.00915.x, indexed in Pubmed: 11153924.

4. Byrd KE. Mandibular movement and muscle activity during mastication in the guinea pig (Cavia porcellus). J Morphol. 1981; 170(2): 147-169, doi: 10.1002/jmor.1051700203, indexed in Pubmed: 7299825.

5. Cox PG, Jeffery N. Reviewing the morphology of the jawclosing musculature in squirrels, rats, and guinea pigs with contrast-enhanced microCT. Anat Rec (Hoboken). 2011; 294(6): 915-928, doi: 10.1002/ar.21381, indexed in Pubmed: 21538924.

6. Druzinsky RE, Doherty AH, De Vree FL. Mammalian masticatory muscles: homology, nomenclature, and diversification. Integr Comp Biol. 2011; 51(2): 224-234, doi: 10.1093/icb/icr067, indexed in Pubmed: 21742777.

7. Druzinsky RE. Functional anatomy of incisal biting in Aplodontia rufa and sciuromorph rodents - part 1: masticatory muscles, skull shape and digging. Cells Tissues Organs. 2010; 191(6): 510-522, doi: 10.1159/000284931, indexed in Pubmed: 20160428.

8. Edoute $Y$, Arieli R, Nevo E. Evidence for improved myocardial oxygen delivery and function during hypoxia in the mole rat. J Comp Physiol B. 1988; 158(5): 575-582, indexed in Pubmed: 3249020.

9. Eroglu F. Çorum city Spalax Leucodon Nordmann. 1840 the caryiological and morphological analysis of Mammalia: Rodentia. Zonguldak Karaelmas University Science. 2006.

10. Gorbunova V, Hine C, Tian X, et al. Cancer resistance in the blind mole rat is mediated by concerted necrotic cell death mechanism. Proc Natl Acad Sci U S A. 2012; 109(47): 19392-19396, doi: 10.1073/pnas.1217211109, indexed in Pubmed: 23129611.

11. Greene EC. Anatomy the Rat. Transactions of the American Ptvlosophical Society. Vol. XXVII, Hainer Publishing Company, New York and London. 1963.

12. Hautier L, Saksiri S. Masticatory muscle architecture in the Laotian rock rat Laonastes aenigmamus (Mammalia, Rodentia): new insights into the evolution of hystricognathy. J Anat. 2009; 215(4): 401-410, doi: 10.1111/j.14697580.2009.01130.x, indexed in Pubmed: 19694873.

13. Herring SW. Masticatory muscles and the skull: a comparative perspective. Arch Oral Biol. 2007; 52(4): 296-299, doi: 10.1016/j.archoralbio.2006.09.010, indexed in Pubmed: 17084804.

14. Hiiemae K, Houston W. The structure and function of the jaw muscles in the rat (Rattus norvegicus L.). Zoological J Linnean Society. 1971; 50(1): 75-99, doi: 10.1111/j.10963642.1971.tb00752.x.

15. Hill JE. Morphology of the pocket gopher mammalian genus thomomys. Univ Calif Publ Zool. 1937; 42: 1-171.

16. Howell $A$. The saltatorial rodent dipodomys: the functional and comparative anatomy of its muscular and osseous systems. Proc Am Acad Arts Scien. 1932; 67(10): 377, doi: $10.2307 / 20022915$. 
17. Illgun R, Yoldas A, Kuru N, et al. Macroscopic anatomy of the lower respiratory system in mole rats (Spalax leucodon). Anat Histol Embryol. 2014; 43(6): 474-481, doi: 10.1111/ahe.12098, indexed in Pubmed: 24450964.

18. Kivanc E. The geographic variations of Turkey Spalax. Ankara (Notes in Turkish. 1988: 72-88.

19. Kleinschmidt T, Nevo E, Braunitzer G. The primary structure of the hemoglobin of the mole rat (Spalax ehrenbergi, rodentia, chromosome species 60 ). Hoppe Seylers Z Physiol Chem. 1984; 365(5): 531-537, indexed in Pubmed: 6469215.

20. Klingener D. The Comparative Myology of Four Dipodoid Rodents: Genera Zapus, Napaeozapus, Sicista, and Jaculus. Front Cover, Museum of Zoology. University of Michigan. 1964.

21. Malik A, Bicker A, Poetzsch G, et al. Hypoxia tolerance, longevity and cancer-resistance in the mole rat Spalax: a liver transcriptomics approach. Scientific Reports. 2017; 7(1), doi: 10.1038/s41598-017-13905-z.

22. Miller G, Gidley J. Synopsis of the supergenerie groups of rodents. J Washington Acad Scien. 1918; 8: 431-448, doi: 10.5962/bhl.part.6490.

23. Musser GG, Carleton MD. Suerfamily Muroidea. In: Wilson DE, Reeder DM (eds.). Mammal Secies of the World: a Taxonomic and Geograhic Reference. 3rd ed. Baltimore: Johns Hokins University Press. 2005: 894-1531.

24. Nevo E. utionary theory and processes of active speciation and adaptive radiation in subterranean mole rats. Spalaxehrenbergisuperspecies in Israel Evol Biology. 1991; 25: 1-125.

25. Norris RW, Zhou K, Zhou C, et al. The phylogenetic position of the zokors (Myospalacinae) and comments on the families of muroids (Rodentia). Mol Phylogenet Evol. 2004; 31(3): 972-978, doi: 10.1016/j.ympev.2003.10.020, indexed in Pubmed: 15120394.

26. Odagiri N, Kubota K, Shibanai S. Density of muscle spindles in the jaw muscles of the Japanese flying squirrel and the guinea pig. Ann Anat. 1993; 175(3): 263-270, indexed in Pubmed: 8338226.

27. Ozkan ZE. Macro-anatomical investigations on the skeletons of mole-rat (Spalax leucodon Nordmann). III. Skeleton axiale. Veterinarski Arhiv. 2077; 7(3): 281-289.

28. Rinker GC. The comparative myology of the mammalian genera Sigmodon, Oryzomys, Neotoma, and Peromyscus (Cricetinae), with remarks on their intergeneric relationships. MiscPublMusZoolUniv Michigan. 1954; 83: 1-124.

29. Satoh K. Mechanical advantage of area of origin for the external pterygoid muscle in two murid rodents,Apodemus speciosus andClethrionomys rufocanus. J Morphol. 1999; 240(1):
1-14, doi: 10.1002/(sici)1097-4687(199904)240:1<1::aidjmor1>3.0.co;2-d.

30. Scapino RP. Biomechanics of Feeding in Carnivora. Chicago. Illinois: Dissertation, University of Illinois. 1968.

31. Shams I, Aaron A, Eviatar N. Hypoxic stress tolerance of the blind subterrean mole rat. Laboratory of Animal Molecular Evolution. Institute of Evolution, University of Haifa, Mount Carmel, Haifa. 2004; 10(1): 9698-9703.

32. Thorington R, Darrow K. Jaw muscles of Old World squirrels. J Morphol. 1996; 230(2): 145-165, doi: 10.1002/(sici)10974687(199611)230:2<145::aid-jmor3>3.0.co;2-g.

33. Turnbull WD. Mammalian masticatory apparatus. Fieldiana Geol. 1970; 18(2): 147-356.

34. Vianey-Liaud M. Possible evolutionary relationships among Eocene and Lower Oligocene rodents of Asia, Europe, and North America. In: Luckett E.W.P., Hartenberger E.J.L.(eds): Evolutionary Relationships among Rodents: A Multidisciplinary Analysis. Plenum Press NATO ASI. New York 1985.

35. Warburton NM. Comparative jaw muscle anatomy in kangaroos, wallabies, and rat-kangaroos (marsupialia: macropodoidea). Anat Rec (Hoboken). 2009; 292(6): 875-884, doi: 10.1002/ar.20905, indexed in Pubmed: 19462457.

36. Weijs W. Morphology of the muscles of mastication in the albino rat Rattusnorvegicus. Acta Morph Neerl-Scand. 1973; 11: 312-340.

37. William PW, Sherri JH. Biomechanical analysis of mastication in the fossil rodent ischyromys and its bearing on the origin of sciuromorphs, Technical Report N.P. Service Paleontology Research. 1993; 2: 21.

38. Wood AE. The evolution of Old World and New World hystricomorphs. In: Rowlands I.W, Weir B.J. (eds): The Biology of Hystricognath Rodents. Academic Press, SympZoolSoc London. 1974; 34: 21-60.

39. Woods CA, Howland EB. Adaptive Radiation of Capromyid Rodents: Anatomy of the Masticatory Apparatus. J Mammal. 1979; 60(1): 95-116, doi: 10.2307/1379762.

40. Woods CA. Comparative myology of jaw, hyoid, and pectoral appendicular regions of new and old world hystricomorph rodents. Bull Am Mus Nat Hist. 1972; 147: 115-198.

41. Yalcın H, Arslan A, Tıpırdamaz S. Macro-anatomical investigations on the masticatory muscles of tree squirrel. Vet. Bilimleri, Dergisi 2003; 19. ; 3(4): 83-88.

42. Zanjani ED, Poster J, Burlington $\mathrm{H}$, et al. Liver as the primary site of erythropoietin formation in the fetus. J Lab Clin Med. 1977; 89(3): 640-644, indexed in Pubmed: 839121. 